\title{
Optimization of a Centrifugal Impeller with the Constraint on Efficiency at the Stall Point
}

\author{
Kaibin Wang, Xin Ai, Ruizi Zhang, Jingyin $\mathrm{Li}^{*}$ \\ School of Energy and Power Engineering, Xi'an Jiaotong University, Xi'an, China \\ Email: ‘jyli@mail.xjtu.edu.cn
}

How to cite this paper: Wang, K.B., Ai, X., Zhang, R.Z. and Li, J.Y. (2018) Optimization of a Centrifugal Impeller with the Constraint on Efficiency at the Stall Point. Open Journal of Fluid Dynamics, 8, 15-29. https://doi.org/10.4236/ojfd.2018.81002

Received: February 7, 2018

Accepted: March 6, 2018

Published: March 9, 2018

Copyright $\odot 2018$ by authors and Scientific Research Publishing Inc. This work is licensed under the Creative Commons Attribution International License (CC BY 4.0).

http://creativecommons.org/licenses/by/4.0/

(c) (i) Open Access

\begin{abstract}
An optimization strategy is presented concerning the aerodynamic performance of an impeller at the design point with a constraint of efficiency at the stall point, on the basis of the combination of three-dimensional inverse design method and the response surface methodology (RSM). A specific inlet angular momentum is given in the prescribed blade loading to facilitate the change of the blade inlet angle at either the hub or shroud of the impeller. Three variables, the inlet angular momentums at both the hub and shroud as well as a coefficient relation with blade loading, were chosen as the optimization variables after a sensitivity analysis, which is conducted by means of the orthogonal design experiment. The candidate impellers were generated by different angular momentum distributions determined by the Box-Behnken design, and the performances of corresponding compressors were simulated. The response surface models of the performances of the compressors were obtained at the design and stall points. Thus the optimal impeller was obtained and the compressor's performance at the design flow rate could be predicted under the constraint of a specified efficiency at the stall flow rate. A comparison between the computational results of the original and optimized impeller indicates that a considerable improvement of the efficiency of the compressor over the whole working range is obtained, which confirms the validity of the optimization strategy.
\end{abstract}

\section{Keywords}

Optimization, Impeller, Inverse Design, Angular Momentum, Aerodynamic Constraint

\section{Introduction}

The centrifugal compressor is the core and main energy-consuming component 
in large refrigeration systems. The refrigeration centrifugal compressor usually has a vaneless diffuser. One important demand for a refrigeration centrifugal compressor is that it can work at low flow rates with a high efficiency.

The design of a high efficiency centrifugal compressor is a forever topic and has attracted much attention of the researchers over the past decades. Many papers have been published, covering almost every aspect. For example, Chen et al. [1] studied the impact of the inlet chamber of a centrifugal compress or on its performance, and found the inlet chamber's distorted flow field degrades the compressor's performance evidently. The entropic efficiency of the compressor at the design flow rate was increased by $1.26 \%$ after an optimization of the chamber shape. Wang et al. [2] investigated the geometry deformation of the impeller due to the temperature increase and the load of centrifugal force, focusing on the impact of variation in tip clearance on the compressor performance. Veress et al. [3] conducted the design and optimization of the vaneless diffuser, bend and return channel of a multistage centrifugal compressor. Their computation shows a rather modest impact on performance, but the flow becomes rather uniform, therefore, a larger operating range can be expected. Oh et al. [4] studied the effects of blade lean on aerodynamic performance of a high-pressure ratio centrifugal impeller. Their results showed that a positive lean at the exit of impeller helps mitigate the secondary flow to contribute to more uniform flows. Rodgers [5] carried out a study to identify the optimal blade number and investigated its effects on efficiency of centrifugal compressor impellers.

It is well known that the impeller is the key component of a centrifugal compressor; therefore, much more researchers conducted investigations on the design and optimization of the impeller. The design and optimization of the impeller could be categorized into two groups: the one based on direct design problems and the other based on inverse design problems.

Concerning the approaches based on direct design problems, the common way is to choose the parameters which are used to parameterize the impeller geometry as design variables directly, and then the geometry of the impeller is optimized by using different optimization techniques. Many papers have been published in this literature, such as the optimizations of the meridional passage shape [6] [7] [8], the optimizations of the blade angle distribution [9] [10], and those of the position and profile of the splitter blade [11] [12]. The optimization approaches adopted in above references include the radial basis neural network method, genetic algorithm, and the response surface methodology.

Although optimization of the impeller geometry by direct method is an effective and intuitional way, but it's not easy to control the blade loading during the optimization process, because it is the blade geometry parameters that are chosen as the design variables. Therefore, instead of parameterizing the unknown blade shape directly, another way is to parameterize the blade loading distribution and obtain the blade geometry by using the inverse design method [13].

In many inverse design investigations, the variable of circulation (angular momentum $\left.\left(\mathrm{rV}_{\theta}\right)\right)$ was brought to represent the blade loading distribution, and 
there are several methods to parameterize the distribution of angular momentum. For example, Yiu and Zangeneh [13] proposed two different control methods, one uses the three-segment method to parameterize the gradient of angular momentum $\left(\mathrm{d}\left(r V_{\theta}\right) / \mathrm{d} m\right)$ distribution, and the other method was to parameterize the $r V_{\theta}$ distribution with the B-spline curve directly. They concluded that the one using the $\mathrm{B}$-spline is a more appropriate method in certain conditions, but the three-segment method is more practical. Gu et al. [14] used the three-order Bezier curve to control the circulation profile on the blade, and studied the impact of three different blade loading types on centrifugal compressor performance at the design condition. Lam et al. [15] used a single three-order polynomial to parameterize the distribution angular momentum $\left(V_{\theta} R\right)$ along the streamline. The three-segment method to parameterize the gradient distribution of angular momentum $\left(\mathrm{d}\left(r V_{\theta}\right) / \mathrm{d} m\right)$, the curve of which has the highest loading in the middle of the blade passage, is in accordance with the impeller or the blade cap Facity. In addition, the blade loading is intuitively represented by the three-segment lines, and can be controlled by only a small amount of parameters. Therefore, many researchers preferred to use this method to prescribe the blade loading in their investigations. For example, Wang [16] used the three-segment distribution of $\mathrm{d}\left(r V_{\theta}\right) / \mathrm{d} m$ which was controlled by four variables, i.e. NC, ND, SLOPE and LE, to carry out their design of the impeller. Bonaiuti and Zangeneh [17] optimized an impeller by prescribing the blade loading in the same manner. Their example confirmed the validity of the design strategy. Moreover, the coupling of response functions with the parameterization of blade loading also allowed for an easy sensitivity analysis of the design parameters on the performance in their investigations.

Although there are many papers published on the optimization of impellers at the design point or on the multi-objective aerodynamic optimization, few papers were published focusing on the aerodynamic optimization of the blade at the design point under the constraint for a certain high efficiency at stall flow rate.

In this paper, an optimization strategy of the impeller is presented. This method optimizes the aerodynamic performance of the impeller at the design point with a demand for a certain high efficiency at the stall flow rate. A similar three-segment distribution of $\mathrm{d}\left(r V_{\theta}\right) / \mathrm{d} m$ was adopted. In addition, a specific inlet angular momentum was specified to alter the blade inlet angle easily. This can account for the performance at off-design points conveniently. On the basis of RSM model, the performances at design and stall points can be expressed, which lay the foundation for the optimization of the impeller under a certain aerodynamic constraint. The optimization strategy was applied to the performance improvement of a refrigerant centrifugal compressor. The success in performance improvement confirmed the validity of the optimization strategy.

\section{Design Parameters of the Compressor and the Numerical Model}

The design parameters of the compressor are listed in Table 1. These parameters 
Table 1. Design parameters of the original compressor.

\begin{tabular}{cc}
\hline Parameters & Data \\
\hline Working fluid & R134a \\
Inlet total temperature/K & 280.3 \\
Inlet total pressure $/ \mathrm{Pa}$ & 368,000 \\
Outlet static pressure $/ \mathrm{Pa}$ & 573,000 \\
Blade number & 17 \\
Design flow rate $/ \mathrm{kg} \cdot \mathrm{s}^{-1}$ & 15.5 \\
Rotating speed $/ \mathrm{r} \cdot \mathrm{min}^{-1}$ & 7940 \\
Static pressure ratio & 1.56 \\
Total pressure ratio & 1.67 \\
\hline
\end{tabular}

are based on a compressor designed by a company. This compressor was carefully designed by using the NREC software. To improve its performance at low flow rates, especially to enlarge its stable operation range, further optimization is needed for this compressor.

To simplify the computations, only the impeller and its followed vaneless diffuser are considered in the simulations in this paper, for the performance of the compressor is mainly affected by these two components. The overall view of the originally designed impeller is shown in Figure 1.

The main dimensional parameters of the original compressor are listed in $\mathrm{Ta}$ ble 2. The flow path in the impeller and the vaneless diffuser is shown in Figure 2.

The hexahedral structured grid is applied in both the passages of the original impeller and the vaneless diffuser by using the software named Turbo-Grid in ANSYS 15.0. Figure 3 shows the grid distributed in a single channel of the original impeller and the diffuser. The flow field and performance of the original compressor were simulated by using the ANSYS CFX 15.0, with the adoption of the $k$ - $\varepsilon$ turbulence model. As is known, the $k-\varepsilon$ turbulence model usually can give fast and reliable predictions. The impeller eye was set as the inlet boundary, with the total temperature and total pressure being set to $280.3 \mathrm{~K}$ and $368,000 \mathrm{~Pa}$, respectively; meanwhile, the outlet of the diffusor was set as the outlet boundary. The outlet mass flow rate is set to $0.91176 \mathrm{~kg} \cdot \mathrm{s}^{-1}$, which is one seventeenth of the design flow rate (single channel). For the interface between the impeller and diffuser, the type of frozen rotor is adopted. The simulation was thought to be convergent when the Root Mean Square (RMS) residual approaches $10^{-5}$.

Grid independence test was also conducted, as shown in Table 3. It can be seen that the grid number of 1,500,000 is sufficient for simulation. The static pressure ratio and the efficiency keep almost unchanged even when the grid number further increases to $2,500,000$, an over $60 \%$ increase in grid number.

The characteristics of the original compressor were simulated by altering the mass flow rate at the outlet boundary, as shown in Figure 4. Figure 4(a) shows 


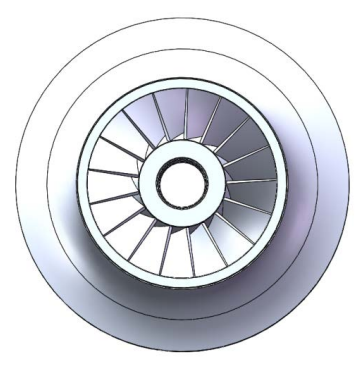

(a)

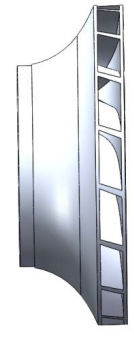

(b)

Figure 1. The original impeller with three dimensional blades.

(a) Front view; (b) Side view.
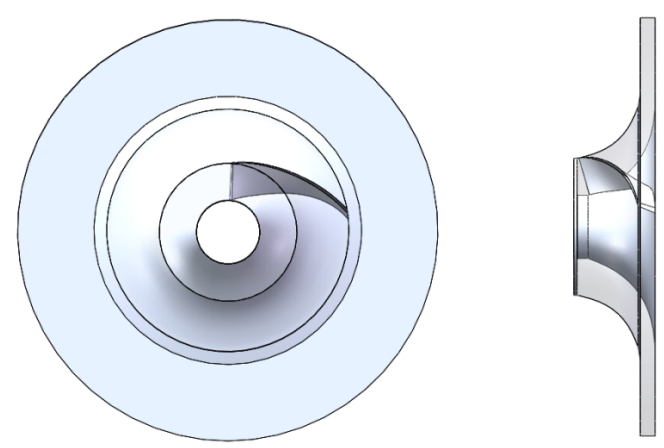

Figure 2. The flow path of the impeller and the diffuser.

Table 2. Main dimensional parameters.

\begin{tabular}{cc}
\hline Variables & Parameters \\
\hline Impeller outlet diameter $\mathrm{D}_{2} / \mathrm{mm}$ & 324 \\
Impeller inlet diameter $\mathrm{D}_{0} / \mathrm{mm}$ & 184 \\
Hub diameter $\mathrm{d} / \mathrm{mm}$ & 85 \\
Impeller outlet width $\mathrm{b}_{2} / \mathrm{mm}$ & 22.79 \\
Axial length $/ \mathrm{mm}$ & 90 \\
Shroud outlet incline angle/ & 18.11 \\
Diffuser inlet width $\mathrm{b}_{3} / \mathrm{mm}$ & 20 \\
Diffuser outlet width $\mathrm{b}_{4} / \mathrm{mm}$ & 20 \\
Diffuser inlet diameter $\mathrm{D}_{3} / \mathrm{mm}$ & 179 \\
Diffuser outlet diameter $\mathrm{D}_{4} / \mathrm{mm}$ & 281 \\
\hline
\end{tabular}

Table 3. Test results of grid independence.

\begin{tabular}{ccc}
\hline Elements & Static pressure ratio & Stage efficiency/\% \\
\hline 500,000 & 1.56 & 94.00 \\
$1,500,000$ & 1.57 & 94.20 \\
$2,500,000$ & 1.57 & 94.26
\end{tabular}




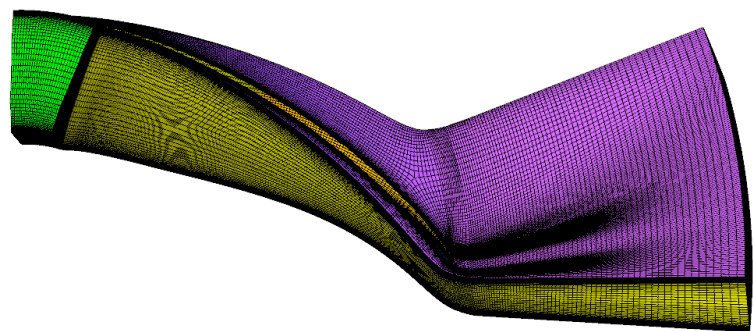

Figure 3. Grid distribution in the impeller and diffuser.

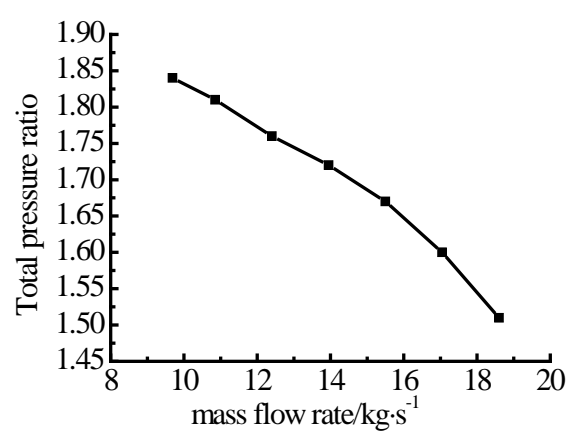

(a)

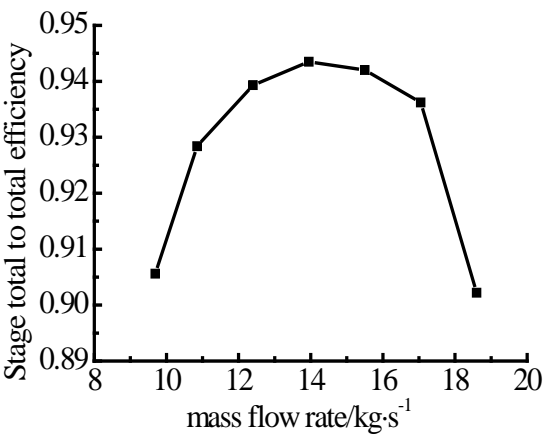

(b)

Figure 4. Performance curves of the original compressor. (a) Total pressure ratio; (b) Total-to-total efficiency.

the total-to-total pressure ratio while Figure 4 (b) shows the corresponding efficiency.

Determining the surge or the rotating stall flow rate is a hard task. Following the approach in Reference [18], when the mass difference between the inlet and outlet boundary exceeds $0.5 \%$ and the residual rises obviously in simulating the flow field, the flow rate is thought to be near the stall point. As shown in Figure 4, the efficiency curve of the original compressor has its peak near the design point, while the pressure ratio increases continuously. When the mass flow rate was reduced to 0.625 times that of the design point, the residual increased considerably even if a very good initial flow field was assumed. Thus, the flow rate of $9.69 \mathrm{~kg} \cdot \mathrm{s}^{-1}$ is regarded as the stall point of the original compressor.

\section{The Angular Momentum Distribution and the Primary Design of the Compressor}

The angular momentum $\left(V_{\theta} R\right)$ along the streamline is directly related to the blade loading. In this paper the impeller flow passage is divided into three parts, which are the inlet transition section 1-L, the middle section L-b and the rear section b-2, respectively, as shown in Figure 5. Section 1-L starts from the inlet of the blade, and its length usually takes one-sixth to one-fifth of the streamline along the blade passage. The position of the $b-b$ line which separates Section L-b and Section b-2 is determined by an imaged radius, $r_{b}$, which is calculated by 


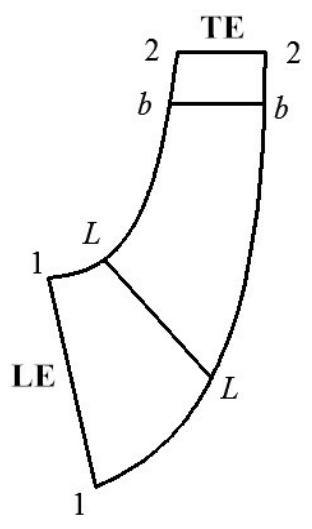

Figure 5. Diagram of the three parts of the blade on the meridian plane.

the following expression.

$$
r_{b}=r_{2} \mathrm{e}^{-0.7 \frac{2 \pi \tau_{2}}{N}}
$$

Here, $r_{2}$ represents the impeller outer radius, $\tau_{2}$ is the blade blocking factor at the outlet and $N$ is blade number.

In the inlet transition Section (1-L), the distribution of the angular momentum along the streamline is expressed as follows:

$$
\left(r V_{\theta}\right)=a_{1} \bar{m}^{4}+b_{1} \bar{m}^{3}+c_{1} \bar{m}^{2}+d_{1} \bar{m}+e_{1}
$$

In the middle section, which is the main Section (L-b) to input shaft work to the fluid, the angular momentum is described as below:

$$
\left(r V_{\theta}\right)=a_{2} \bar{m}^{2}+b_{2} \bar{m}+c_{2}
$$

In the rear Section (b-2), the slip effect of the flow from the blade is to be considered. The angular momentum distribution is assumed by the following expression:

$$
\left(r V_{\theta}\right)=a_{3} \bar{m}^{3}+b_{3} \bar{m}^{2}+c_{3} \bar{m}+d_{3}
$$

In above formula, $\bar{m}$ is the normalized stream wise length, $\bar{m}=m / m_{2}$, and its value is between 0 and 1 . In most of the design of impeller, it is usually assumed that there is no pre-swirl air flow at the blade inlet and the flow incidence angle equals 0 , which means that $\left(V_{\theta} R\right)_{1}=0$ and $\mathrm{d}\left(V_{\theta} R\right) /\left.\mathrm{d} \bar{m}\right|_{1}=0$; additionally, it is also assumed that $\mathrm{d}^{2}\left(V_{\theta} R\right) /\left.\mathrm{d} \bar{m}^{2}\right|_{1}$ equals to 0 . On the other hand, the angular momentum reaches its maximum value $\left(V_{\theta} R\right)_{\max }$ at the blade outlet, and it is also prescribed that $\mathrm{d}\left(V_{\theta} R\right) /\left.\mathrm{d} \bar{m}\right|_{2}=0$. Due to the requirement for smoothness at the connections between the regions, the first-order derivative on both sides of the two connection points ( $\mathrm{L}$ and $\mathrm{b}$ ) should have the same value. The diagrams of the distribution of the $V_{\theta} R$ and its derivative along the streamline are shown in Figure 6, in which the derivative, $\mathrm{d}\left(V_{\theta} R\right) / \mathrm{d} \bar{m}$, represents the blade loading.

A primary design of the impeller was conducted first by assuming a reasonable angular momentum distribution, similar to those shown in Figure 6. At this 


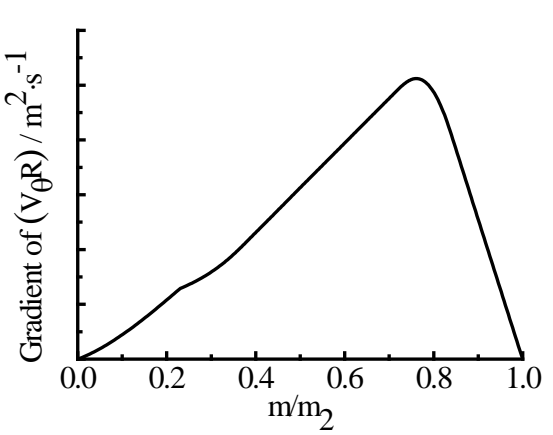

(a)

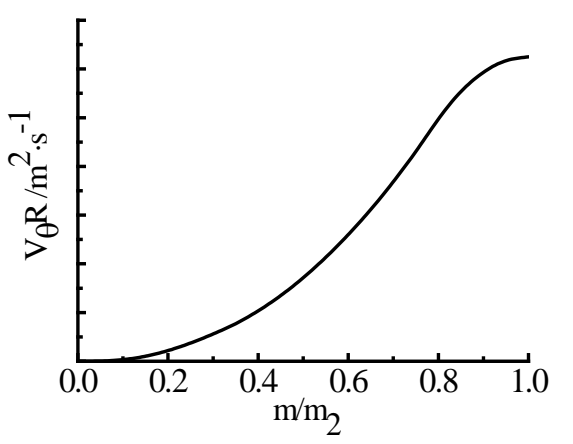

(b)

Figure 6. Schematic diagram of blade loading distribution. (a) Gradient of angular momentum; (b) Angular momentum.

stage, the focus was to optimize the meridional flow path of the impeller, and the outlet width and diameter of the impeller. The diameter of the impeller was only enlarged a little to facilitate the implantation of the new impeller into the compressor. The vaneless diffusor was still adopted. After the primary design, the stall flow rate was further reduced to $9.30 \mathrm{~kg} \cdot \mathrm{s}^{-1}$ as much as 0.6 times that of the design point. The simulated results show that the efficiency of the primary compressor at the design point is inferior to that of the original compressor. Therefore, it is necessary to further optimize the blade shape of the primary impeller on the basis of the optimized meridional plane and the main impeller parameters.

\section{The Sensitivity Analysis of the Parameters in the Angular Momentum Formula}

In the expressions of the angular momentum distribution along the streamlines, a coefficient $K$ is introduced. The coefficient $K$ is defined as the ratio of the derivative terms at the two points, $\mathrm{L}$ and b, i.e.

$K=\left(\mathrm{d}\left(V_{\theta} R\right) /\left.\mathrm{d} \bar{m}\right|_{b}\right) /\left(\mathrm{d}\left(V_{\theta} R\right) /\left.\mathrm{d} \bar{m}\right|_{L}\right)$. In this paper, the $V_{\theta} R$ distribution along the streamline is solved by giving the blade inlet angular momentum and the coefficient $K$, with a given angular momentum at the blade outlet. In fact, the $V_{\theta} R$ at the outlet is a given data and is determined by the total input shaft work needed in the impeller. In the present investigation, the $V_{\theta} R$ at the outlet has a little higher value near the shroud and a little lower value near the hub (the mean value being the input work needed). Thus, only four variables are chosen to optimize the angular momentum along the streamlines at both the hub and the shroud (the inlet $V_{\theta} R$ and the $K$ ).

To identify the optimization variables which should have great impact on the compressor performance, the orthogonal design experiment is applied to conduct the sensitivity analysis of the parameters. In this investigation the orthogonal design table $\mathrm{L} 9\left(3^{4}\right)$ is adopted, in which each factor is divided into 3 levels.

To improve the performance at the stall point, it is better to choose negative values of the angular momentum at the inlet of the blade near the shroud and 
the hub, for this would lead to a small inlet blade angle and could help enlarge the operational range to a smaller flow rates. The three levels for both the $V_{\theta} R_{\text {shroud }}$ and the $V_{\theta} R_{\text {hub }}$ are given as $-0.75 \mathrm{~m}^{2} \cdot \mathrm{s}^{-1},-0.50 \mathrm{~m}^{2} \cdot \mathrm{s}^{-1},-0.25 \mathrm{~m}^{2} \cdot \mathrm{s}^{-1}$. Additionally, aft-loaded distribution near the hub and shroud can effectively reduce the secondary flows on the suction side of blade, according to the investigations of References [19] [20]. Thus aft-loaded distribution is applied, and the coefficient $K$ at shroud ( $\left.K_{\text {shroud }}\right)$ and hub $\left(K_{\text {hub }}\right)$ are both divided into three levels, i.e., 3.5, 3 and 2.5. The details of the levels and the design scheme are listed in Table 4.

Nine impellers were generated according to the combinations of the different levels, as shown in Table 4. The efficiencies of the nine compressors at both the design and the stall flow rates were simulated. The computational results are shown in Table 5.

To select factors which have higher influences on the compressor efficiency, range analysis is applied to the simulating results. According to the range analysis results shown in Table 6 , at the design flow rate, $V_{\theta} R_{h u b}$, the inlet angular

Table 4. Design scheme of orthogonal design experiment.

\begin{tabular}{ccccc}
\hline Schemes & $V_{\theta} R_{\text {shroud }} / \mathrm{m}^{2} \cdot \mathrm{s}^{-1}$ & $V_{\theta} R_{\text {hub }} / \mathrm{m}^{2} \cdot \mathrm{s}^{-1}$ & $K_{\text {shroud }}$ & $K_{\text {hub }}$ \\
\hline 1 & -0.75 & -0.75 & 3.5 & 3.5 \\
2 & -0.75 & -0.5 & 3 & 3 \\
3 & -0.75 & -0.25 & 2.5 & 2.5 \\
4 & -0.5 & -0.75 & 3 & 2.5 \\
5 & -0.5 & -0.5 & 2.5 & 3.5 \\
6 & -0.5 & -0.25 & 3.5 & 3 \\
7 & -0.25 & -0.75 & 2.5 & 3 \\
8 & -0.25 & -0.5 & 3.5 & 2.5 \\
9 & -0.25 & -0.25 & 3 & 3.5 \\
\hline
\end{tabular}

Table 5. Numerical results of the nine orthogonal designs.

\begin{tabular}{ccc}
\hline Schemes & $\begin{array}{c}\text { Total-to-total efficiency at design } \\
\text { condition/\% }\end{array}$ & $\begin{array}{c}\text { Total-to-total efficiency at stall } \\
\text { condition/\% }\end{array}$ \\
\hline 1 & 93.38 & 91.25 \\
2 & 93.62 & 91.09 \\
3 & 93.88 & 91.13 \\
4 & 93.62 & 91.07 \\
5 & 93.73 & 90.58 \\
6 & 93.86 & 90.75 \\
7 & 93.7 & 90.4 \\
8 & 93.8 & 90.77 \\
9 & 93.96 & 90.26 \\
\hline
\end{tabular}


momentum of the blade near the hub, has the greatest impact on the total-to-total efficiency, while the coefficient of $K_{h u b}$ has the least influence on efficiency. Table 7 shows the range analysis of efficiency at the stall flow rate. Unlike the trend shown in Table 6, under this condition, $V_{\theta} R_{\text {shroud }}$ plays the most important role in efficiency, but the $V_{\theta} R_{h u b}$ is the weakest influential factor.

The optimal objective is to maximize the efficiency at the design point with the constraint of a demand for the efficiency at the stall point; therefore, three factors, i.e. $V_{\theta} R_{\text {shroud }} V_{\theta} R_{\text {hub }}$ and $K_{\text {shroud }}$ are chosen as the optimization variablesin the following optimization process.

\section{Response Surface-Based Optimization Scheme}

To generate the response surface, the Box-Behnken design is adopted to obtain the interpolating data. Based on the previous range analysis, the three variables, i.e. $V_{\theta} R_{\text {shroud }} V_{\theta} R_{\text {hub }}$ and $K_{\text {shroud }}$ are chosen as the optimization variables, and they are all given three levels.

The limits of the three variables are chosen as follows in the first loop of optimization. The coefficient $K_{\text {shroud }}$ is chosen in the range of 2.0 to 4.0. For the angular momentums, they are chosen as $0 \leq V_{\theta} R_{h u b} \leq 0.8 \mathrm{~m}^{2} \cdot \mathrm{s}^{-1}$ and $-0.8 \mathrm{~m}^{2} \cdot \mathrm{s}^{-1} \leq$ $V_{\theta} R_{\text {shroud }} \leq 0$, because the variable of $V_{\theta} R_{h u b}$ is the most important factor at the design point, while $V_{\theta} R_{\text {shroud }}$ is the most important factor at the stall point. The reason for choosing a negative range for the $V_{\theta} R_{\text {shroud }}$ is that, the low mass flow rate at the stall point would lead to a low inlet air angle, so a negative prescribed $V_{\theta} R$ would be better for improving the efficiency at stall flow rate. The same principle is applied for the $V_{\theta} R_{h u b}$. However, the optimization results show that

Table 6. Range analysis of the total-to-total efficiency at the design point.

\begin{tabular}{ccccc}
\hline \multirow{2}{*}{ Levels } & \multicolumn{4}{c}{ Average of efficiency/\% } \\
\cline { 2 - 4 } & $V_{\theta} R_{\text {shroud }} / \mathrm{m}^{2} \cdot \mathrm{s}^{-1}$ & $V_{\theta} R_{\text {hub }} / \mathrm{m}^{2} \cdot \mathrm{s}^{-1}$ & $K_{\text {shroud }}$ & $K_{\text {hub }}$ \\
\hline 1 & 93.63 & 93.57 & 93.68 & 93.69 \\
2 & 93.74 & 93.72 & 93.73 & 93.73 \\
Range & 93.82 & 93.9 & 93.77 & 93.77 \\
\hline
\end{tabular}

Table 7. Range analysis of the total-to-total efficiency at the stall point.

\begin{tabular}{ccccc}
\hline \multirow{2}{*}{ Levels } & \multicolumn{4}{c}{ Average of efficiency/\% } \\
\cline { 2 - 5 } & $V_{\theta} R_{\text {shroud }} / \mathrm{m}^{2} \cdot \mathrm{s}^{-1}$ & $V_{\theta} R_{\text {hub }} / \mathrm{m}^{2} \cdot \mathrm{s}^{-1}$ & $K_{\text {shroud }}$ & $K_{\text {hub }}$ \\
\hline 1 & 91.16 & 90.91 & 90.92 & 90.7 \\
2 & 90.8 & 90.81 & 90.81 & 90.75 \\
3 & 90.48 & 90.71 & 90.7 & 90.99 \\
Range & 0.68 & 0.19 & 0.22 & 0.29 \\
\hline
\end{tabular}


the optimal value of $V_{\theta} R_{\text {shroud }}$ lies on the lower boundary $\left(-0.8 \mathrm{~m}^{2} \cdot \mathrm{s}^{-1}\right)$, and the optimal value of $V_{\theta} R_{h u b}$ also lies on the lower limit $\left(0 \mathrm{~m}^{2} \cdot \mathrm{s}^{-1}\right)$. Moreover, from the contour map of the response surface of the efficiency at the design point, it is found that a bigger positive value of $V_{\theta} R_{h u b}$ would lead to a high efficiency. The optimal coefficient of $K_{\text {shroud }}$ is 2.85 , which means the range is proper.

The second loop of optimization was conducted on the basis of the first loop of optimization. In this optimization process, the range of $V_{\theta} R_{h u b}$ is from0.6 $\mathrm{m}^{2} \cdot \mathrm{s}^{-1}$ to $1.4 \mathrm{~m}^{2} \cdot \mathrm{s}^{-1}$, meanwhile, $V_{\theta} R_{\text {shroud }}$ is in the range of $-0.6 \mathrm{~m}^{2} \cdot \mathrm{s}^{-1}$ to -1.4 $\mathrm{m}^{2} \cdot \mathrm{s}^{-1}$, with the coefficient $K$ being still in the same range as before, i.e. $2 \leq K \leq$ 4. In this loop, the scheme of the design of experiment is shown in Table 8. The simulation results of the corresponding schemes are listed Table 9.

On the basis of the simulation results, the second order polynomial expression for the total-to-total efficiency of the compressor at the design point can be generated as follows:

$$
\begin{aligned}
\eta_{d e}= & 94.34+0.15 A+0.005 B-0.14 C-0.005 A B+0.030 A C \\
& -0.060 B C-0.030 A^{2}-0.090 B^{2}+0.0056 C^{2}
\end{aligned}
$$

Here, $A, B$ and $C$ represent the variables of the $V_{\theta} R_{\text {shrouc }} V_{\theta} R_{\text {hub }}$ and $K_{\text {shrouc }}$ respectively. According to the results of variance analysis, the P-value of the fitting equation is lower than 0.01 , which means the fitting equation is significant.

\begin{tabular}{|c|c|c|c|}
\hline Schemes & $V_{\theta} R_{\text {shroud }} / \mathrm{m}^{2} \cdot \mathrm{s}^{-1}$ & $V_{\theta} R_{h u b} / \mathrm{m}^{2} \cdot \mathrm{s}^{-1}$ & $\mathrm{~K}_{\text {shroud }}$ \\
\hline 1 & -0.6 & 1.4 & 3 \\
\hline 2 & -1.4 & 1 & 2 \\
\hline 3 & -1 & 0.6 & 2 \\
\hline 4 & -1.4 & 1 & 4 \\
\hline 5 & -1 & 1 & 3 \\
\hline 6 & -1 & 1.4 & 4 \\
\hline 7 & -1 & 1 & 3 \\
\hline 8 & -0.6 & 1 & 4 \\
\hline 9 & -1 & 1.4 & 2 \\
\hline 10 & -1 & 1 & 3 \\
\hline 11 & -1.4 & 1.4 & 3 \\
\hline 12 & -1 & 0.6 & 4 \\
\hline 13 & -1 & 1 & 3 \\
\hline 14 & -0.6 & 1 & 2 \\
\hline 15 & -0.6 & 0.6 & 3 \\
\hline 16 & -1.4 & 0.6 & 3 \\
\hline 17 & -1 & 1 & 3 \\
\hline
\end{tabular}

Table 8. Schemes of the design of experiment of the second loop of optimization. 
Table 9. Numerical results of nine designed compressors.

\begin{tabular}{|c|c|c|}
\hline \multirow[t]{2}{*}{ Scheme } & $\begin{array}{l}\text { Total-to-total efficiency at } \\
\text { design condition }\end{array}$ & $\begin{array}{c}\text { Total-to-total efficiency at } \\
\text { stall condition }\end{array}$ \\
\hline & $1 \%$ & $1 \%$ \\
\hline 1 & 94.34 & 90.2 \\
\hline 2 & 94.2 & 91.21 \\
\hline 3 & 94.37 & 89.94 \\
\hline 4 & 94.05 & 91.6 \\
\hline 5 & 94.4 & 91.11 \\
\hline 6 & 94.13 & 91.03 \\
\hline 7 & 94.12 & 91.09 \\
\hline 8 & 94.42 & 90.56 \\
\hline 9 & 94.54 & 90.3 \\
\hline 10 & 94.38 & 91.08 \\
\hline 11 & 94.08 & 91.3 \\
\hline 12 & 94.2 & 91.11 \\
\hline 13 & 94.4 & 91.1 \\
\hline 14 & 94.63 & 89.1 \\
\hline 15 & 94.38 & 89.54 \\
\hline 16 & 94.1 & 91.4 \\
\hline 17 & 94.42 & 91.12 \\
\hline
\end{tabular}

The test of the lack off it of the equation shows P-value equals to 0.0595 , which means the lack of fit is not significant. Therefore, the response surface model is good enough to be used for optimization.

In the same manner, the functional form of the RSM model for the total-to-total efficiency at the stall point is shown as below:

$$
\begin{aligned}
\eta_{s p}= & 91.10-0.83 A+0.056 B+0.48 C+0.29 A B+0.24 A C \\
& -0.011 B C-0.17 A^{2}-0.22 B^{2}-0.29 C^{2}
\end{aligned}
$$

The P-value of the above fitting equation is lower than 0.01 , which means the fitting equation is also significant. The lack off it of the equation shows its P-value equals 0.0669 , a value greater than 0.05 . This indicates that the lack off it is not significant. This RSM model is also qualified to predict the efficiency of the compressor at the stall point.

The refrigeration compressor often operates at off-design conditions, especially at low flow rates. In addition, it is often required to operate at its lowest flow rate with the demanded efficiency. In this optimization, a minimum value of the efficiency of compressor at its stall point is set as $91.3 \%$. Under this constraint, the efficiency of the compressor at the design point is optimized. The optimization was conducted by using the software, Design-Expert, with the fitting 
Equation (5) and Equation (6) obtained above. The optimal values of the three variables, $V_{\theta} R_{\text {shroud }}, V_{\theta} R_{\text {hub }}$ and $K_{\text {shroud }}$ are $-1.40 \mathrm{~m}^{2} \cdot \mathrm{s}^{-1}, 1.02 \mathrm{~m}^{2} \cdot \mathrm{s}^{-1}$ and 2.10 , respectively. The predicted optimal total-to-total efficiency at the design point is $94.37 \%$.

To show the improvement effect of the optimization, the optimized impeller was incorporated into the compressor model. The performance of the compressor was simulated by using the same grid strategy and computational model. The comparison of the performance between the primary design and the optimized design of the compressor is shown in Figure 7(a) and Figure 7(b). It can be seen that the improvement of the performance is evident, especially at the design point. In addition, the total-to-total efficiency of the optimized compressor reaches $94.37 \%$ at the design point and $91.25 \%$ at the stall point, respectively, which means the predictions of the surrogate functions show good agreements compared with numerical simulations.

As shown in Figure 8(a) and Figure 8(b), the comparison of the performance between the original and the optimized compressor are also conducted. It can be seen that the improvement of the performance at the stall point is evident, in addition to an enlarged operational range. The efficiency at the design point is also improved, despite that the pressure ratio is increased over the whole range.

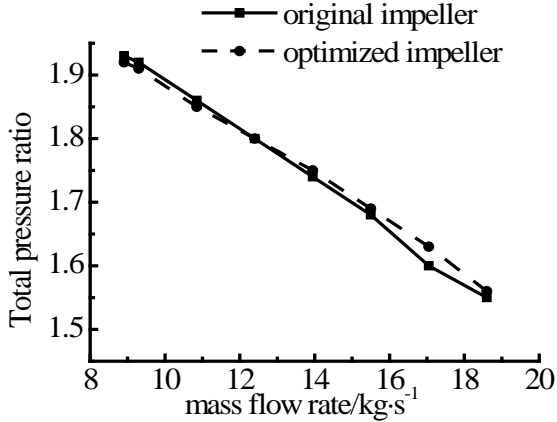

(a)

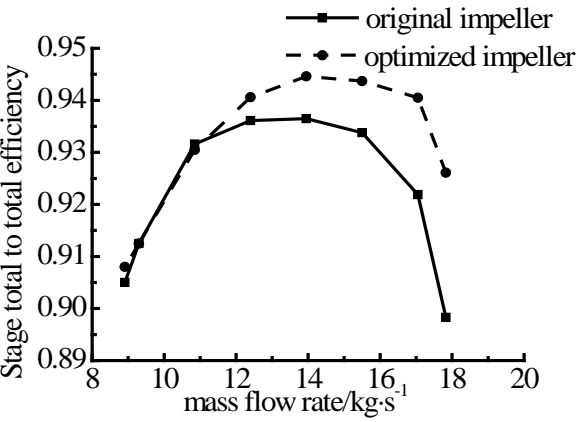

(b)

Figure 7. Performance comparison between optimized and primary compressor. (a) Total pressure ratio; (b) Total-to-total efficiency.

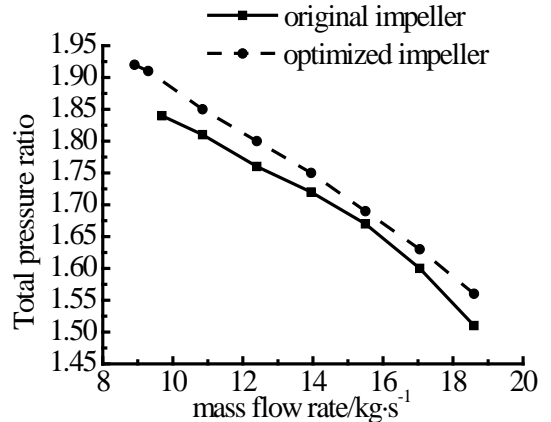

(a)

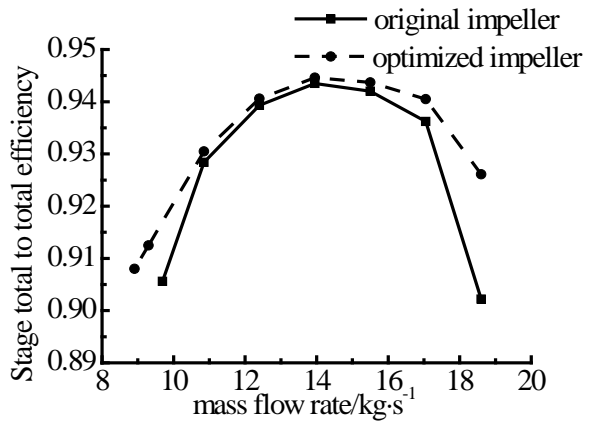

(b)

Figure 8. Performance comparison between optimized and original impeller. (a) Total pressure ratio; (b) Total-to-total efficiency. 


\section{Conclusions}

This paper presents the optimization strategy of a compressor with a high pressure ratio. Based on the RSM model, the efficiencies of the compressor under two different working conditions can be fitted well. Therefore, the RSM model can be used to optimize the efficiency at design flow rate, with constraint of the demanded efficiency at stall flow rate. The improvement of the optimized compressor is evident.

The change in the inlet angular momentum can effectively alter the inlet angle of the blade, which could enhance the performance of the compressor and also enlarge its operation range. In addition, the parameter sensitivity analysis shows that the inlet angular momentum near the hub $\left(V_{\theta} R_{\text {hub }}\right)$ has the greatest impact on the efficiency at the design point of the impeller; while the inlet angular momentum near shroud ( $V_{\theta} R_{\text {shroud }}$ ) is the most important factor for the efficiency at the stall point.

\section{Acknowledgements}

This work is supported by National Natural Science Foundation of China under Contract (No. 51276137).

\section{References}

[1] Chen, Z.H., Gu, C.G. and Shu, X.W. (2010) Shape Optimum Design for Centrifugal Compressor Radial Inlet Based on CFD Technique. Journal of Mechanical Engineering, 46, 124-129. (In Chinese) https://doi.org/10.3901/JME.2010.14.124

[2] Wang, H.L., Xi, G., Li, J.Y. and Yuan, M.J. (2011) Effect of the Tip Clearance Variation on the Performance of a Centrifugal Compressor with Considering Impeller Deformation. Proceedings of the Institution of Mechanical Engineers Part A-Journal of Power And Energy, 225, 1143-1155. https://doi.org/10.1177/0957650911416914

[3] Veress, A., Den, R.V. and Braembussche (2004) Inverse Design and Optimization of a Return Channel for a Multistage Centrifugal Compressor. Journal of Fluids Engineering, 126, 799-806. https://doi.org/10.1115/1.1792258

[4] Oh, J.S., Buckley, C.W. and Agrawal, G.L. (2011) Numerical Study on the Effects of Blade Lean on High-Pressure Centrifugal Impeller Performance. ASME 2011 Turbo Expo: Turbine Technical Conference and Exposition, Vancouver, British Columbia, Canada, 6-10 June 2011, 1957-1969. https://doi.org/10.1115/GT2011-45383

[5] Rodgers, C. (2000) Effects of Blade Number on the Efficiency of Centrifugal Compressor Impellers. ASME Turbo Expo 2000: Power for Land, Sea, and Air, Munich, 8-11 May 2000, 1-8.

[6] Kim, J.H., Choi, J.H and Kim, K.Y. (2009) Design Optimization of a Centrifugal Compressor Impeller Using Radial Basis Neural Network Method. ASME Turbo Expo, Orlando, 8-12 June 2009, 443-451. https://doi.org/10.1115/GT2009-59666

[7] Kim, J.H., Choi, J.H., Husain, A. and Kim, K.Y. (2009) Design Optimization of a Centrifugal Compressor Impeller by Multi-Objective Genetic Algorithm. ASME Fluids Engineering Conference, Vail, 2-6 August 2009, 185-191. https://doi.org/10.1115/FEDSM2009-78486

[8] Kim, J.H., Choi, J.H., Husain, A. and Kim, K.Y. (2010) Multi-Objective Optimiza- 
tion of a Centrifugal Compressor Impeller Through Evolutionary Algorithms. Proceedings of the Institution of Mechanical Engineers Part A Journal of Power \& Energy, 224, 711-721. https://doi.org/10.1243/09576509JPE884

[9] Kim, S., Park, J., Ahn, K. and Baek, J. (2010) Numerical Investigation and Validation of the Optimization of a Centrifugal Compressor Using a Response Surface Method. Proceedings of the Institution of Mechanical Engineers Part A Journal of Power \& Energy, 224, 251-259. https://doi.org/10.1243/09576509JPE842

[10] Bonaiuti, D., Arnone, A., Ermini, M. and Baldassarre, L. (2006) Analysis and Optimization of Transonic Centrifugal Compressor Impellers Using the Design of Experiments Technique. Journal of Turbomachinery, 128, 786-797. https://doi.org/10.1115/1.1579507

[11] Torshizi, S.A.M., Benisi, A.H. and Durali, M. (2016) Numerical Optimization and Manufacturing of the Impeller of a Centrifugal Compressor by Variation of Splitter Blades. ASME Turbo Expo 2016: Turbomachinery Technical Conference and Exposition, Seoul, 13-17 June 2016, 1-7.

[12] Torshizi, S.A.M., Benisi, A.H. and Durali, M. (2017) Multilevel Optimization of the Splitter Blade Profile in the Impeller of a Centrifugal Compressor. ScientiaIranica, 24, 707-714.

[13] Yiu, K.F.C. and Zangeneh, M. (2000) Three-Dimensional Automatic Optimization Method for Turbomachinery Blade Design. Journal of Propulsion \& Power, 16, 1174-1181. https://doi.org/10.2514/2.5694

[14] Gu, C.W., Chen, L., Wu, P. and Dai, R. (2013) Design and Optimization for Centrifugal Impeller S2 Streamsheet Based on Circulation Profile. Fluid Machinery, 41, 24-28. (In Chinese)

[15] Lam, K., Qi, D.T. and Pomfret, M.J. (1998) A Two-Dimensional Inverse Design Method for Impeller Blade Profiles of Centrifugal Fans. HKIE Transactions, 5, 113-119.

[16] Wang, P. (2017) Multi-Objective Design of a Transonic Turbocharger Compressor with Reduced Noise and Increased Efficiency. Ph.D. Thesis, UCL University, London.

[17] Bonaiuti, D. and Zangeneh, M. (2009) On the Coupling of Inverse Design and Optimization Techniques for the Multiobjective, Multipoint Design of Turbomachinery Blades. Journal of Turbomachinery, 131, 1-16. https://doi.org/10.1115/1.2950065

[18] MAO, Y.F. (2016) Numerical Study of Correlation between the Surge of Centrifugal Compressor and the Piping System. Ph.D. Thesis, Xi'an Jiaotong University, Xi'an. (In Chinese)

[19] Zangeneh, M., Goto, A. and Harada, H. (1998) On the Design Criteria for Suppression of Secondary Flows in Centrifugal and Mixed Flow Impellers. Journal of Turbomachinery, 120, 723-735. https://doi.org/10.1115/1.2841783

[20] Zangeneh, M., Amarel, N., Daneshkhah, K. and Krain, H. (2011) Optimization of 6.2: 1 Pressure Ratio Centrifugal Compressor Impeller by 3D Inverse Design. ASME 2011 Turbo Expo: Turbine Technical Conference and Exposition, Vancouver, British Columbia, Canada, 6-10 June 2011, 2167-2177. 